\title{
Using New Gas Exchange Methods to Estimate Mesophyll Conductance and Non-stomatal Inhibition of Photosynthesis Caused by Water Deficits
}

\author{
James Bunce ${ }^{1}$ \\ Crop Systems and Global Change Laboratory, USDA-ARS, Beltsville Agricultural Research Center, \\ 10300 Baltimore Avenue, Beltsville, MD 20705-2350
}

Additional index words. Glycine max, Phaseolus vulgaris, Brassica oleracea, Abutilon theophrasti, stomatal conductance, water stress

\begin{abstract}
Soil water deficits remain one of the most important factors reducing the yield of crop plants and may become even more limiting with changes in the global climate and competition for fresh water resources. Soil water deficits reduce plant growth partly by reducing photosynthesis. However, it remains unclear how important non-stomatal factors are in limiting photosynthesis under moderate water stress and whether rising atmospheric carbon dioxide may alter which processes limit photosynthesis under water stress. The conductance to $\mathrm{CO}_{2}$ from the substomatal air space to the site of carboxylation inside chloroplasts in $\mathrm{C}_{3}$ plants is now termed mesophyll conductance. Because of the competition between $\mathrm{CO}_{2}$ and $\mathrm{O}_{2}$ for RuBisco, the carbon dioxide concentration at the chloroplast can be estimated from the $\mathrm{O}_{2}$ sensitivity of photosynthesis, providing a new method of estimating mesophyll conductance. It has also recently been realized that partial stomatal closure resulting from water stress can often be reversed by exposing leaves to low $\mathrm{CO}_{2}$. This provides a new means of assessing the non-stomatal component of the inhibition of photosynthesis by water stress. These methods were applied to four $C_{3}$ species and revealed that mesophyll conductance decreased substantially with water stress in two of the four species and that reopening of stomata did not eliminate the reduction in photosynthesis caused by moderate water stress at either the current ambient or elevated $\mathrm{CO}_{2}$ concentrations.
\end{abstract}

Insufficient water is currently one of the environmental factors most limiting to crop yields and is likely to remain so even with global climate change. Although rising atmospheric carbon dioxide concentrations may substantially reduce stomatal conductance $\left(g_{\mathrm{S}}\right)$, we can expect this to result in only small reductions in evapotranspiration at the field scale (Bunce, 2004). Furthermore, despite projected increased global precipitation, the increased magnitude of rainfall events also leads to a prediction of increased frequency of drought (Groisman and Knight, 2008). Therefore, adapting crops to drought conditions remains a reasonable goal.

Dry soils reduce plant biomass production primarily by slowing leaf area development or by decreasing photosynthesis, although reproductive processes can be more sensitive and specific targets of stress in some species. In many crops, dry conditions occur after full canopy development so that slowing of leaf area development would have little impact on biomass production, but reduced photosynthesis would limit it. Thus, improvement of photosynthesis during dry conditions is a worthwhile objective. Strategies to improve photosynthesis during drought should be based on knowledge of what plant processes are most limiting to photosynthesis in stressed plants.

Received for publication 20 Sept. 2011. Accepted for publication 2 Nov. 2011.

This paper was part of the colloquium, "Emerging Techniques to Evaluate and Mitigate Crop Environmental Stress in a Changing Climate" held 28 Sept. 2011 at the ASHS Conference, Waikoloa, HI, and sponsored by the Environmental Stress Physiology (STRS) Working Group.

${ }^{1}$ To whom reprint requests should be addressed; e-mail James.Bunce@ars.usda.gov.
It is generally accepted that moderate water stress inhibits photosynthesis primarily by decreasing $g_{\mathrm{S}}$, which limits the carbon dioxide supply to the leaf interior (Flexas et al., 2004; Flexas and Medrano, 2002; Lawlor and Cornic, 2002). At higher atmospheric carbon dioxide concentrations, the stomatal limitation to photosynthesis decreases (Sage, 2004), and photosynthesis would be expected to be less inhibited by the same relative reduction in $g_{\mathrm{s}}$. However, assessments of stomatal and biochemical limitations to photosynthesis need to take into account new information about limitations to photosynthesis imposed by the movement of carbon dioxide from inside the stomata to the site of fixation inside the chloroplast, the "mesophyll conductance," and how it may be affected by water stress and by carbon dioxide concentration as well as taking into account the wellknown difficulties in leaf gas exchange analysis presented by "patchy" stomatal closure.

Mesophyll conductance has been measured primarily using chlorophyll-a fluorescence combined with leaf gas exchange (Harley et al., 1992) or online carbon isotope discrimination (Evans et al., 1986). These methods rely on uncertain assumptions and involve expensive instrumentation. The oxygen sensitivity of photosynthesis is determined by the carbon dioxide concentration at Rubisco and so provides a relatively inexpensive estimate of mesophyll conductance (Bunce, 2009) and its environmental dependence. The observation that mesophyll conductance can decrease with water stress (e.g., Warren, 2008) calls into question the use of small-scale fluorescence methods to indicate the presence of "patchy" stomatal behavior (Flexas et al., 2004). As an alternative method of assessing the importance of patchy stomatal behavior, we can exploit the fact that stomata can be reopened despite water stress by treatment with low carbon dioxide concentrations (Bunce, 2007; Centritto et al., 2003) and use this to separate stomatal and non-stomatal inhibition of photosynthesis by water stress.

I report the use of the oxygen sensitivity of photosynthesis and exposure to low carbon dioxide concentrations to reopen stomata of moderately stressed leaves of four $\mathrm{C}_{3}$ species to better understand the stomatal and nonstomatal limitations to photosynthesis at the current ambient and projected future carbon dioxide concentrations.

\section{MATERIAL AND METHODS}

Three crop species, soybean (Glycine max L. Merr. cv. Kent), collard (Brassica oleracea acephala DC., variety Georgia Southern), and bean (Phaseolus vulgaris L. variety Dark Red Kidney), and one weedy species, velvetleaf (Abutilon theophrasti L., collected in Beltsville, MD), were grown in controlled environment chambers at $23{ }^{\circ} \mathrm{C}$, which is the growing season mean temperature in Beltsville. There were $12 \mathrm{~h}$ per day of light at 1000 $\mu \mathrm{mol} \cdot \mathrm{m}^{-2} \cdot \mathrm{s}^{-1}$ photosynthetic photon flux density $(P P F D)$ from a mixture of high-pressure sodium and metal halide lamps. Plants were grown one per pot in $20-\mathrm{cm}$ diameter pots, rooted in vermiculite, and fertilized daily with a complete nutrient solution containing $14.5 \mathrm{~mm}$ nitrogen. The chamber air saturation deficit for water vapor was $\approx 1 \mathrm{kPa}$ in the daytime, and the chamber carbon dioxide concentration was controlled at $375 \pm 20$ $\mu \mathrm{mol} \cdot \mathrm{mol}^{-1} 24 \mathrm{~h}$ per day. Leaf gas exchange measurements were made on third main stem trifoliolate leaves in soybean and bean and sixth main stem leaves in collards and velvetleaf a few days after those leaves had reached full area expansion. Water deficits were produced by ending watering for 3 to $5 \mathrm{~d}$. 
Carbon dioxide assimilation rate (A), $g_{\mathrm{S}}$ to water vapor, and substomatal carbon dioxide concentration $\left(\mathrm{C}_{\mathrm{i}}\right)$ were measured on control and water stressed leaves using a Li6400 portable photosynthesis system. Leaves were held at a temperature of $23{ }^{\circ} \mathrm{C}$, a $P P F D$ of $2000 \mu \mathrm{mol} \cdot \mathrm{m}^{-2} \cdot \mathrm{s}^{-1}$, and a leaf to air water vapor saturation deficit of $1.0 \mathrm{kPa}$. Steadystate responses of $\mathrm{A}$ to $\mathrm{C}_{\mathrm{i}}$ over the range of $\approx 100$ to $600 \mu \mathrm{mol} \cdot \mathrm{mol}^{-1}$ were determined at $21 \%$ and $2 \% \mathrm{O}_{2}$ using standard precautions and tests for leaks of water vapor and carbon dioxide through the chamber materials and the seals between leaves and chamber gaskets (compare with Bunce, 2009, 2010). For waterstressed leaves, responses of $A$ to $\mathrm{C}_{\mathrm{i}}$ at $21 \% \mathrm{O}_{2}$ were also determined after first exposing the leaves to an external carbon dioxide concentration of $100 \mu \mathrm{mol} \cdot \mathrm{mol}^{-1}$ until $g_{\mathrm{S}}$ increased as much as it would. As many A vs. $C_{i}$ points as possible were then determined before $g_{\mathrm{S}}$ began to decrease. When $g_{\mathrm{S}}$ began to decrease, the stomata were reopened again by exposure to low carbon dioxide concentration and then more $A$ vs. $C_{i}$ points recorded. After these non-steady state responses were determined, steady-state rates were remeasured at the growth carbon dioxide concentration to determine whether initial rates were again achieved. Water potentials of leaf discs excised from the leaves in which gas exchange was determined were measured using dew point hygrometry.

For control plants, composite A vs. $\mathrm{C}_{\mathrm{i}}$ curves at $21 \%$ and $2 \%\left[\mathrm{O}_{2}\right]$ were used to determine whether mesophyll conductance $\left(\mathrm{g}_{\mathrm{m}}\right)$ varied with $\mathrm{C}_{\mathrm{i}}$ (Bunce, 2010). Briefly, this was done by fitting the A vs. $\mathrm{C}_{\mathrm{i}}$ curves at $21 \%\left[\mathrm{O}_{2}\right]$ to a Farquhar-type biochemical model of $\mathrm{C}_{3}$ photosynthesis and then finding the value of $g_{m}$ at which the model correctly predicted the observed rates at $2 \%\left[\mathrm{O}_{2}\right]$ at that $\mathrm{C}_{\mathrm{c}}$ (Bunce, 2009). This can be done at any $\mathrm{C}_{\mathrm{i}}$, provided rates at both $\left[\mathrm{O}_{2}\right]$ are limited by the same biochemical factor (i.e., either the maximum rate of Rubisco carboxylation, $\mathrm{V}_{\mathrm{Cmax}}$, or the rate of electron transport, J), and provided that $\left[\mathrm{CO}_{2}\right]$ remains limiting to A at both $\left[\mathrm{O}_{2}\right]$. For stressed plants, estimates of $g_{m}$ were done on an individual leaf basis comparing $\mathrm{g}_{\mathrm{m}}$ at the $\mathrm{C}_{\mathrm{i}}$ obtained when $\mathrm{C}_{\mathrm{a}}$ was $\approx 375 \mu \mathrm{mol} \cdot \mathrm{mol}^{-1}$ and in bean only also at $\approx 200 \mu \mathrm{mol} \cdot \mathrm{mol}^{-1}$. These estimates of $\mathrm{g}_{\mathrm{m}}$ allowed the calculation of $\mathrm{V}_{\mathrm{Cmax}}$ based on $\mathrm{C}_{\mathrm{c}}$ rather than $\mathrm{C}_{\mathrm{i}}$ from the lower parts of the $\mathrm{A}$ vs. $C_{i}$ curve and the determination of whether $\mathrm{V}_{\mathrm{Cmax}}$ was affected by water stress. I also determined whether any reduction in $\mathrm{V}_{\mathrm{Cmax}}$ by water stress was reversed by the reopening of stomata. A at a $C_{i}$ of 550 to $600 \mu \mathrm{mol} \cdot \mathrm{mol}^{-1}$ was used to estimate $J$, because $C_{i}$ at that $C_{a}$ was above the transition from $V_{C \max }$ to $\mathrm{J}$ limitation. It was also tested whether reopening of stomata restored any apparent reduction in $\mathrm{J}$ by the water stress. These measurements were conducted on four unstressed plants of each species and five or six moderately stressed plants of each species. The driest plants measured had stomatal conductances reduced to $25 \%$ to $30 \%$ of the maximum for each species when measured at the growth $\left[\mathrm{CO}_{2}\right]$. The $g_{\mathrm{S}}$ of these "moderately stressed" leaves in all cases exceeded $150 \mu \mathrm{mol} \cdot \mathrm{m}^{-2} \cdot \mathrm{s}^{-1}$.

\section{RESULTS AND DISCUSSION}

In unstressed plants, $\mathrm{g}_{\mathrm{m}}$ changed by $15 \%$ or less over the $C_{i}$ range of 100 to $400 \mu \mathrm{mol} \cdot \mathrm{mol}^{-1}$ in all species except bean (Fig. 1). Responses in bean and soybean were similar to those previously reported (Bunce, 2010) with an $\approx 60 \%$ decrease in $\mathrm{g}_{\mathrm{m}}$ as $\mathrm{C}_{\mathrm{i}}$ increased from 100 to $300 \mu \mathrm{mol} \cdot \mathrm{mol}^{-1}$ in bean. Others, using various methods of estimating $\mathrm{g}_{\mathrm{m}}$, have also found it to decrease with increasing $\mathrm{CO}_{2}$ in some species (compare with Flexas et al., 2008) or to change very little with $\mathrm{CO}_{2}$ in other species (e.g., Bunce, 2010; Schaufele et al., 2011).

The leaf water potentials of stressed plants in this study averaged $-0.7 \mathrm{MPa}$ in bean, $-0.9 \mathrm{MPa}$ in collard, $-1.3 \mathrm{MPa}$ in soybean, and $-1.6 \mathrm{MPa}$ in velvetleaf. Flexas and Medrano (2002) argued that water stress effects on photosynthesis are better characterized by the absolute value of $g_{\mathrm{S}}$ than by water potential. Because all of the $g_{\mathrm{S}}$ values in this study were greater than $0.15 \mathrm{~mol} \cdot \mathrm{m}^{-2} \cdot \mathrm{s}^{-1}$, these would be considered mild or moderate water stress in the Flexas and Medrano (2002) scheme.

Water stress decreased $g_{m}$ measured at the growth $\mathrm{C}_{\mathrm{a}}$ in collard and velvetleaf but not in bean or soybean (Table 1). No decrease in $g_{m}$ with stress was also observed in bean at a lower $\mathrm{C}_{\mathrm{a}}$ of $\approx 200 \mu \mathrm{mol} \cdot \mathrm{mol}^{-1}$ (not shown). The lack of response of $g_{m}$ to water stress in soybean is the same result as previously reported for moderately stressed leaves of a different variety of that species (Bunce, 2009). Others have observed decreases in $g_{m}$ with water stress in many but not all species (reviewed in Flexas et al., 2008; Warren, 2006) and also after the application of abscisic acid (Schaufele et al., 2011).

The importance of $g_{m}$ as a limitation to photosynthesis is reflected in the ratio of $\mathrm{C}_{\mathrm{c}}$ to $\mathrm{C}_{\mathrm{i}}$ with ratios close to 1 indicating little limitation. For unstressed leaves, collard had the highest $C_{c}$ to $C_{i}$ ratio of the species examined (Table 1). In all species except collard, the $\mathrm{C}_{\mathrm{c}}$ to $\mathrm{C}_{\mathrm{i}}$ ratio increased in moderately stressed leaves, indicating that $\mathrm{g}_{\mathrm{m}}$ became less limiting to photosynthesis during water stress. In collard, the increase in $\mathrm{g}_{\mathrm{m}}$ with stress resulted in essentially no change in the $C_{c}$ to $C_{i}$ ratio with stress. Thus, there were no species in which the limitation
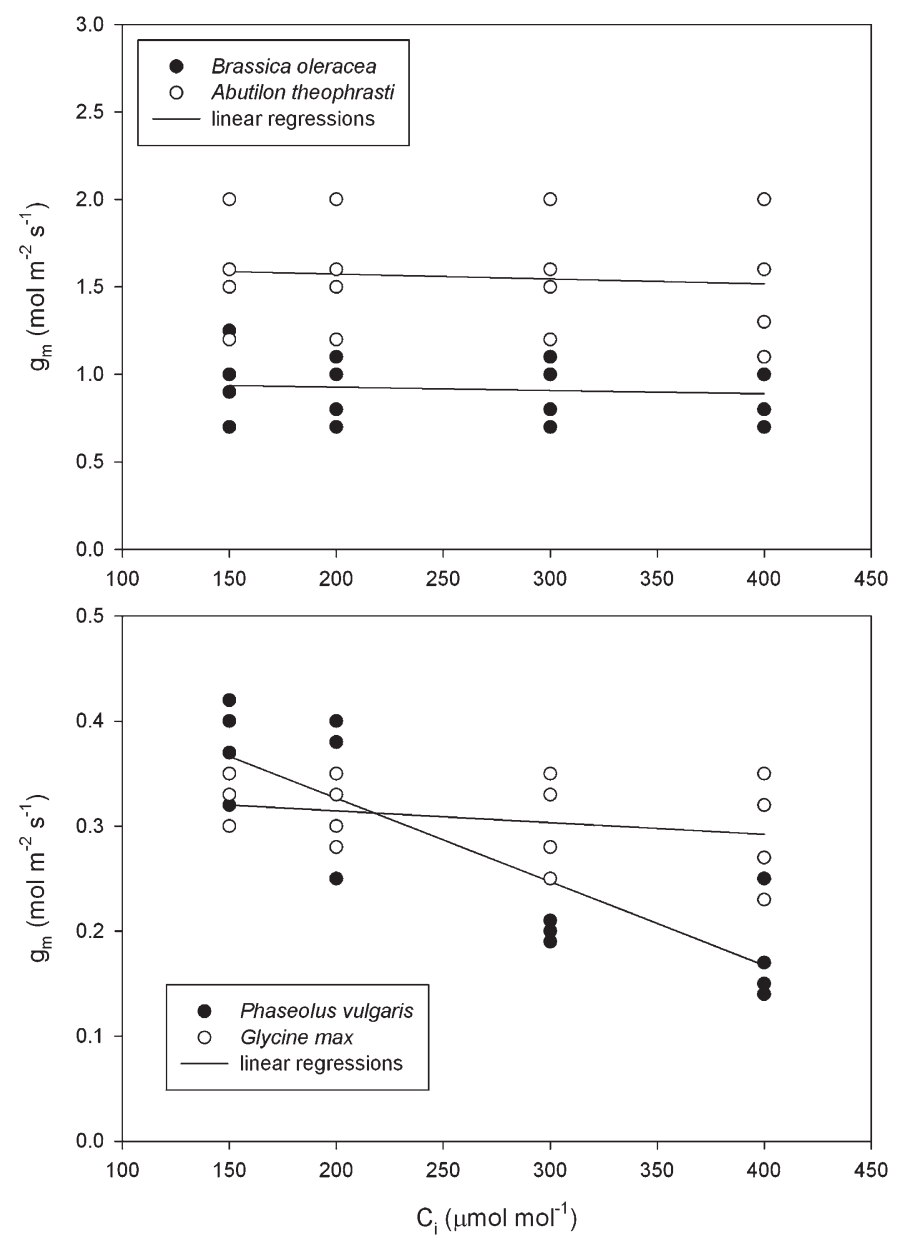

Fig. 1. Mesophyll conductance $\left(g_{m}\right)$ measured over a range of carbon dioxide concentration $\left(\mathrm{C}_{\mathrm{i}}\right)$ values in four leaves of each of four species. $r^{2}$ values of linear regressions were: Brassica oleracea 0.011 , Abutilon theophrasti 0.008, Phaseolus vulgaris 0.66, and Glycine max 0.086. 
Table $1 . \mathrm{C}_{\mathrm{c}}$ to $\mathrm{C}_{\mathrm{i}}$ ratio \pm SE for control and moderately stressed leaves of four species. ${ }^{\mathrm{z}}$

\begin{tabular}{lcc}
\hline Species & $\mathrm{C}_{\mathrm{c}} / \mathrm{C}_{\mathrm{i}}$ control & $\mathrm{C}_{\mathrm{c}} / \mathrm{C}_{\mathrm{i}}$ stressed \\
Soybean & $0.65 \pm 0.02$ & $0.76 \pm 0.03$ \\
Collard & $0.88 \pm 0.02$ & $0.86 \pm 0.04$ \\
Bean & $0.61 \pm 0.04$ & $0.70 \pm 0.04$ \\
Velvetleaf & $0.72 \pm 0.01$ & $0.89 \pm 0.02$ \\
\hline
\end{tabular}

${ }^{2}$ The ratio was estimated for $\mathrm{C}_{\mathrm{a}}=375 \mu \mathrm{mol} \cdot \mathrm{mol}^{-1}$ for four control and five or six stressed leaves per species.

$\mathrm{C}_{\mathrm{i}}=$ carbon dioxide concentration.

to photosynthesis imposed by $\mathrm{g}_{\mathrm{m}}$ increased with water stress.

$\mathrm{V}_{\mathrm{Cmax}}$, estimated from $\mathrm{C}_{\mathrm{c}}$, decreased in stressed plants of all species as did J (Table 2). Decreases in $\mathrm{V}_{\text {Cmax }}$ by these moderate levels of water stress differ from the generalization that decreased Rubisco activity requires very low stomatal or mesophyll conductances (Galmes et al., 2011). The relative decreases in $\mathrm{g}_{\mathrm{m}}, \mathrm{V}_{\mathrm{Cmax}}$, and $\mathrm{J}$ varied among species with $\mathrm{g}_{\mathrm{m}}$ decreasing particularly strongly in collard, $\mathrm{V}_{\mathrm{Cmax}}$ in bean, and $\mathrm{J}$ in soybean. The relative decrease in photosynthesis with water stress was not substantially or consistently less at $\mathrm{C}_{\mathrm{a}}=550$ than at $\mathrm{C}_{\mathrm{a}}=375$ (Table 2). The substantial reduction in $\mathrm{A}$ at $\mathrm{C}_{\mathrm{a}}=550$ $\mu \mathrm{mol} \cdot \mathrm{mol}^{-1}$ with stress can be primarily ascribed to the reduction in $\mathrm{J}$, which occurred in all species. Thus, elevated measurement $\mathrm{CO}_{2}$, despite decreasing the stomatal limitation of photosynthesis in control leaves, did not protect photosynthesis from the effects of water stress. The substantial inhibition of photosynthesis by water stress when measured at elevated $\mathrm{CO}_{2}$ is consistent with the generalization that RuBp regeneration and ATP production, which influence $\mathrm{J}$, are impaired by mild to moderate water stress (Flexas and Medrano, 2002; Lawlor and Cornic, 2002). The relative reduction in $g_{\mathrm{S}}$ with water stress in all cases was slightly larger at the higher measurement $\mathrm{C}_{\mathrm{a}}$. This is consistent with other observations of increased sensitivity of $g_{S}$ to $C_{i}$ in water-stressed leaves (Bunce, 2007).

Exposure to low $\mathrm{CO}_{2}$ increased $g_{\mathrm{S}}$ of moderately water-stressed leaves by least a factor of 3 for all species (Table 3). The largest relative increase occurred in soybean, in which stomatal conductances equaled those of control leaves measured at the growth $\mathrm{C}_{\mathrm{a}}$ despite having initially been decreased to $\approx 25 \%$ of the unstressed value. In the other species, the maximum $g_{\mathrm{S}}$ achieved during reopening was $\approx 80 \%$ of the control values (measured at the growth $\mathrm{C}_{\mathrm{a}}$ ).

Species differed in whether reopening of stomata of water-stressed leaves reversed decreases in specific photosynthetic parameters. Decreases in $V_{\text {Cmax }}$ with stress were partially reversed by reopening stomata in collard but were unaffected by reopening in the other species (Table 3 ). Decreases in $\mathrm{J}$ with stress were partially reversed in soybean, bean, and collard but were not completely reversed in any of these species. An example of A vs. $C_{i}$ curves before and after complete reopening of stomata in soybean is given in Figure 2, illustrating the lack of improvement in the initial part of the A vs.
$\mathrm{C}_{\mathrm{i}}$ curve and only partial improvement in the upper part of the curve. The decreases in $g_{m}$ with stress in collard and velvetleaf were unaffected by stomatal reopening. This result differs from the reversal of the decrease in $\mathrm{g}_{\mathrm{m}}$ caused by salt stress after stomata were reopened (Centritto et al., 2003). In velvetleaf, reopening stomata did not change the inhibition of any of the measured photosynthetic parameters. In none of the four species did reopening of stomata completely reverse the inhibition of photosynthesis caused by water stress. All species continued to show reductions in $\mathrm{g}_{\mathrm{m}}, \mathrm{V}_{\mathrm{Cmax}}$, or $\mathrm{J}$ after reopening of stomata. Reopening of stomata came closest to reversing the effects of water stress on photosynthesis in soybean and collard, which suggests that stomatal closure was relatively more important to the inhibition of photosynthesis by water stress in those species and that biochemical disruptions were relatively more important in bean and velvetleaf. In bean and velvetleaf, $27 \%$ to $39 \%$ reductions in photosynthesis with stress only improved to $17 \%$ to $27 \%$ reductions after stomata were reopened.

\section{CONCLUSIONS}

Although mesophyll conductance decreased substantially with moderate water stress in collard and velvetleaf, mesophyll conductance did not increase in importance as a limitation to photosynthesis in any species as a result of water stress. Elevated carbon dioxide concentration did not substantially decrease the inhibition of photosynthesis by moderate water stress, partly

Table 2. Steady-state responses of leaf gas exchange to moderate water stress. ${ }^{\mathrm{z}}$

\begin{tabular}{|c|c|c|c|c|c|c|c|}
\hline \multirow[b]{2}{*}{ Species } & \multicolumn{7}{|c|}{ Percent decrease relative to control } \\
\hline & A375 & A550 & $g_{\mathrm{S}} 375$ & $g_{\mathrm{S}} 550$ & $\mathrm{~g}_{\mathrm{m}}$ & $\mathrm{V}_{\mathrm{Cmax}}$ & $\mathrm{J}$ \\
\hline Soybean & $38 \pm 4$ & $43 \pm 5$ & $75 \pm 3$ & $82 \pm 5$ & $0 \pm 10$ & $23 \pm 5$ & $75 \pm 15$ \\
\hline Collard & $42 \pm 6$ & $34 \pm 5$ & $74 \pm 3$ & $80 \pm 4$ & $36 \pm 8$ & $18 \pm 4$ & $52 \pm 10$ \\
\hline Bean & $35 \pm 5$ & $39 \pm 5$ & $66 \pm 4$ & $73 \pm 5$ & $0 \pm 8$ & $32 \pm 7$ & $50 \pm 12$ \\
\hline Velvetleaf & $30 \pm 2$ & $27 \pm 4$ & $72 \pm 4$ & $76 \pm 4$ & $17 \pm 5$ & $21 \pm 7$ & $21 \pm 6$ \\
\hline
\end{tabular}

${ }^{\mathrm{z}} \mathrm{A}, \mathrm{J}$, and $g_{\mathrm{S}}$ were measured at $21 \%\left[\mathrm{O}_{2}\right]$ at both 375 and $550 \mu \mathrm{mol} \cdot \mathrm{mol}^{-1} \mathrm{C}_{\mathrm{a}}$. Values are means $\pm \mathrm{sE}$, for $\mathrm{n}=5$ or 6 .

$\mathrm{A}=$ assimilation rate; $g_{\mathrm{S}}=$ stomatal conductance; $\mathrm{g}_{\mathrm{m}}=$ mesophyll conductance; $\mathrm{V}_{\mathrm{Cmax}}=$ maximum rate of Rubisco carboxylation; $\mathrm{J}=$ rate of electron transport.

Table 3. Responses of leaf gas exchange to moderate water stress after reopening of the stomata using low $\mathrm{CO}_{2}{ }^{\mathrm{z}}$

\begin{tabular}{lrcccrc}
\hline & \multicolumn{5}{c}{ Percent decrease relative to control } \\
\cline { 2 - 7 } Species & A375 & A550 & \multicolumn{1}{c}{$g_{\mathrm{S}}$} & $\mathrm{g}_{\mathrm{m}}$ & $\mathrm{V}_{\mathrm{Cmax}}$ & $\mathrm{J}$ \\
\hline Soybean & $7 \pm 5$ & $10 \pm 5$ & $0 \pm 11$ & $0 \pm 8$ & $23 \pm 7$ & $15 \pm 4$ \\
Collard & $12 \pm 7$ & $10 \pm 6$ & $17 \pm 9$ & $36 \pm 10$ & $5 \pm 7$ & $16 \pm 5$ \\
Bean & $27 \pm 5$ & $23 \pm 6$ & $19 \pm 7$ & $0 \pm 5$ & $32 \pm 9$ & $27 \pm 7$ \\
Velvetleaf & $20 \pm 4$ & $17 \pm 3$ & $22 \pm 12$ & $17 \pm 4$ & $21 \pm 5$ & $21 \pm 6$ \\
\hline
\end{tabular}

${ }^{\mathrm{z}} \mathrm{A}, \mathrm{J}$, and $g_{\mathrm{S}}$ were measured at $21 \%\left[\mathrm{O}_{2}\right]$ at both 375 and $550 \mu \mathrm{mol} \cdot \mathrm{mol}^{-1} \mathrm{C}_{\mathrm{a}}$. The decrease in $g_{\mathrm{S}}$ is expressed relative to control plants measured at $375 \mu \mathrm{mol} \cdot \mathrm{mol}^{-1}$. Values are means $\pm \mathrm{se}$, for $\mathrm{n}=5$ or 6 . $\mathrm{A}=$ assimilation rate; $g_{\mathrm{S}}=$ stomatal conductance; $\mathrm{g}_{\mathrm{m}}=$ mesophyll conductance; $\mathrm{V}_{\mathrm{Cmax}}=$ maximum rate of Rubisco carboxylation; $\mathrm{J}=$ rate of electron transport.

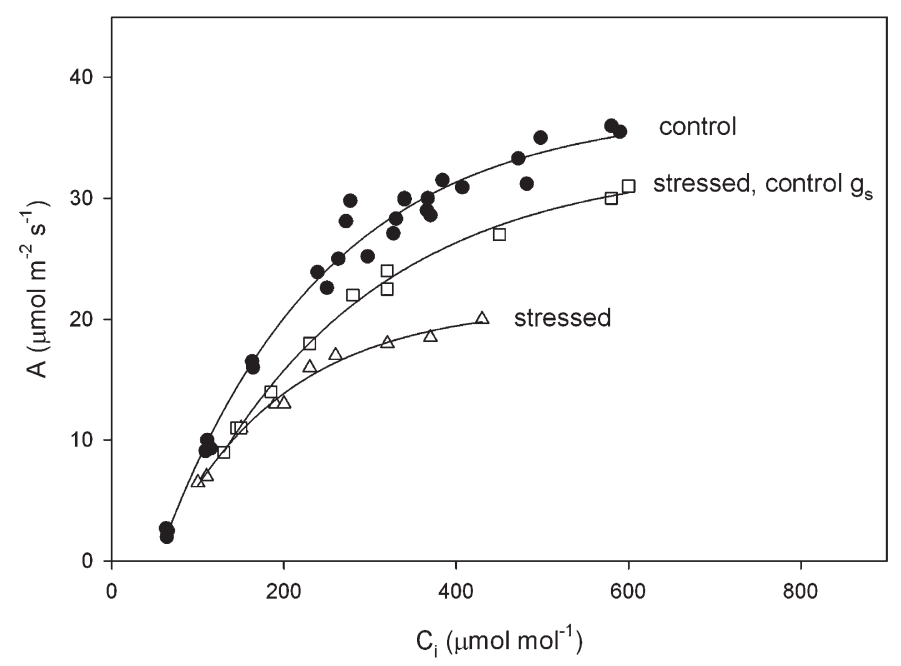

Fig. 2. Photosynthetic $\mathrm{CO}_{2}$ assimilation rate $(\mathrm{A})$ at different carbon dioxide concentration $\left(\mathrm{C}_{\mathrm{i}}\right)$ values in G. $\max$ leaves. Measurements are from unstressed (control) leaves, leaves under moderate water stress, and leaves under moderate water stress, which have had stomata reopened to the value of control leaves by exposing them briefly to a $\left[\mathrm{CO}_{2}\right]$ of $\approx 100 \mu \mathrm{mol} \cdot \mathrm{mol}^{-1}$. 
because of increased sensitivity of $g_{\mathrm{S}}$ to stress at elevated carbon dioxide and partly because a reduction in Rubp regeneration with stress was important in all species. Reopening of stomata during water stress showed that although decreased $g_{\mathrm{S}}$ was the dominant cause of the reduction in photosynthesis in all species, it was not the exclusive cause of reduced photosynthesis in any species. Very substantial non-stomatal inhibition of photosynthesis by moderate water stress occurred in bean and velvetleaf. Disruptions to the regeneration of Rubp may become increasingly important to photosynthesis during water stress as atmospheric carbon dioxide concentration rises. Rubp regeneration also occurs in guard cells and might also be involved in stomatal closure during water stress (Lawson et al., 2003). Thus, prevention of the disruption of Rubp regeneration could prove a useful target for the improvement of the tolerance of photosynthesis to water stress both in the current and future climates.

\section{Literature Cited}

Bunce, J.A. 2004. Carbon dioxide effects on stomatal responses to the environment and water use by crops under field conditions. Oecolgia 140:1-10.

Bunce, J.A. 2007. Low carbon dioxide concentrations can reverse stomatal closure during water stress. Physiol. Plant. 130:552-559.
Bunce, J.A. 2009. Use of the response of photosynthesis to oxygen to estimate mesophyll conductance to carbon dioxide in waterstressed soybean leaves. Plant Cell Environ. $32: 875-881$.

Bunce, J.A. 2010. Variable responses of mesophyll conductance to substomatal carbon dioxide concentration in common bean and soybean Photosynthetica 48:507-512.

Centritto, M., F. Loreto, and K. Chartzoulakis. 2003. The use of low $\left[\mathrm{CO}_{2}\right]$ to estimate diffusional and non-diffusional limitations of photosynthetic capacity of salt-stressed olive saplings. Plant Cell Environ. 26:585-594.

Evans, J.R., T.D. Sharkey, J.A. Berry, and G.D Farquhar. 1986. Carbon isotope discrimination measured concurrently with gas exchange to investigate $\mathrm{CO}_{2}$ diffusion in leaves of higher plants. Aust. J. Plant Physiol. 13:281292.

Flexas, J., J. Bota, F. Loreto, G. Cornic, and T.D. Sharkey. 2004. Diffusive and metabolic limitations to photosynthesis under drought and salinity in $\mathrm{C}_{3}$ plants. Plant Biol. 6:1-11.

Flexas, J. and H. Medrano. 2002. Drought-inhibition of photosynthesis in $\mathrm{C}_{3}$ plants: Stomatal and non-stomatal limitations revisited. Ann. Bot. (Lond.) 89:183-189.

Flexas, J., M. Ribas-Cabo, A. Diaz-Espefo, J. Galmes, and H. Medrano. 2008. Mesophyll conductance to $\mathrm{CO}_{2}$ : Current knowledge and future prospects. Plant Cell Environ. 31:602-621.

Galmes, J., M. Ribas-Carbo, H. Medrano, and J. Flexas. 2011. Rubisco activity in Mediterranean species is regulated by the chloroplastic
$\mathrm{CO}_{2}$ concentration under water stress. J. Expt. Bot. 62:653-665.

Groisman, P.Ya. and R.W. Knight. 2008. Prolonged dry episodes over the conterminous United States: New tendencies emerging during the last 40 years. J. Clim. 21:1850-1862.

Harley, P.C., F. Loreto, G. Di Marco, and T.D. Sharkey. 1992. Theoretical considerations when estimating the mesophyll conductance to $\mathrm{CO}_{2}$ flux by the analysis of the response of photosynthesis to $\mathrm{CO}_{2}$. Plant Physiol. 98:1429-1436.

Lawlor, D.W. and G. Cornic. 2002. Photosynthetic carbon assimilation and associated metabolism in relation to water deficits in higher plants. Plant Cell Environ. 25:275-294.

Lawson, T., K. Oxborough, J.I.L. Morison, and N.R. Baker. 2003. The responses of guard and mesophyll cell photosynthesis to $\mathrm{CO}_{2}, \mathrm{O}_{2}$, light and water stress in a range of species are similar. J. Expt. Bot. 54:1743-1752.

Sage, R.F. 2004. Acclimation of photosynthesis to increasing atmospheric $\mathrm{CO}_{2}$ : The gas exchange perspective. Photosynth. Res. 39:351-368.

Schaufele, R., J. Santrucek, and H. Schyder. 2011. Dynamic changes of canopy-scale mesophyll conductance to $\mathrm{CO}_{2}$ diffusion of sunflower as affected by $\mathrm{CO}_{2}$ concentrationand abscisic acid. Plant Cell Environ. 34:127-136.

Warren, C.R. 2006. Estimating the internal conductance to $\mathrm{CO}_{2}$ movement. Funct. Plant Biol. $33: 432-442$.

Warren, C.R. 2008. Soil water deficits decrease the internal conductance to $\mathrm{CO}_{2}$ transfer but atmospheric water deficits do not. J. Expt. Bot. 59:327-334. 